\title{
вмј Global Health Large-scale public venues as medical emergency sites in disasters: lessons from COVID-19 and the use of Fangcang shelter hospitals in Wuhan, China
}

Dongping Fang, ${ }^{1}$ Shengjie Pan, ${ }^{1}$ Zaishang Li, ${ }^{1}$ Ting Yuan, ${ }^{2}$ Benran Jiang, ${ }^{3}$ Di Gan, ${ }^{4}$ Bai Sheng, ${ }^{5}$ Jing Han, ${ }^{6}$ Tao Wang (I) , ${ }^{4}$ Zhongmin Liu ${ }^{4}$

To cite: Fang D, Pan S, Li Z, et al. Large-scale public venues as medical emergency sites in disasters: lessons from COVID-19 and the use of Fangcang shelter hospitals in Wuhan, China. BMJ Global Health 2020;5:e002815. doi:10.1136/ bmjgh-2020-002815

Handling editor Seye Abimbola

$\mathrm{DF}, \mathrm{SP}, \mathrm{ZL}, \mathrm{TY}, \mathrm{BJ}$ and DG contributed equally.

Received 3 May 2020

Revised 23 May 2020

Accepted 26 May 2020
Check for updates

(c) Author(s) (or their employer(s)) 2020. Re-use permitted under CC BY-NC. No commercial re-use. See rights and permissions. Published by BMJ

For numbered affiliations see end of article.

\section{Correspondence to} Dr Zhongmin Liu; zhongmin_liu_seh@sina.com and

Dr Tao Wang;

happywt0403@126.com

\section{ABSTRACT}

Since the COVID-19 outbreak, Wuhan has adopted three methods of admitting patients for treatment: designated hospitals, newly built temporary hospitals and Fangcang shelter hospitals. It has been proven that converting large-scale public venues such as stadiums and exhibition centres into Fangcang shelter hospitals, which serve as hospitals for isolation, treatment and disease monitoring of patients with mild symptoms, is the most effective way to control virus transmission and reduce mortality. This paper presents some experiences learnt from treating COVID-19 in Wuhan, the first city to report the outbreak and which suffered from a shortage of emergency supplies, heavy workload among staff and a shortage of hospital beds during the early stages of the pandemic. The experiences include location, accessibility, spacious outdoor area, spacious indoor space, power supply, architectural layout design and partition isolation, ventilation, sewage, and problems in the construction and management of Fangcang shelter hospitals. During the COVID-19 pandemic, traditional approaches to disaster preparedness have demonstrated intrinsic problems, such as poor economic performance, inefficiency and lack of flexibility. Converting large-scale public venues into Fangcang shelter hospitals is an important means to rapidly improve the function of the city's healthcare system during a pandemic. This valuable experience in Wuhan will help other countries in their battle against the current COVID-19 pandemic and will also contribute to disaster preparedness and mitigation in the future.

\section{INTRODUCTION}

The COVID-19 pandemic has spread to almost all countries around the world, resulting in significant social and economic losses. Wuhan, which was the first Chinese city to report the outbreak, suffered from a shortage of emergency supplies, heavy workload among staff and a shortage of hospital beds during the early stages of the pandemic.

\section{Summary box}

In the early stage of the COVID-19 pandemic in Wuhan, which was the first Chinese city to report the outbreak, the role of traditional approaches in preparing for this disaster was very limited.

- Since the COVID-19 outbreak, Wuhan has adopted three methods of admitting patients for treatment: designated hospitals, newly built temporary hospitals and Fangcang shelter hospitals.

- Wuhan converted large-scale public venues into Fangcang shelter hospitals, which provided essential living and medical conditions for isolated patients with mild symptoms as well as for suspected patients.

- Converting large-scale public venues into Fangcang shelter hospitals is an effective and efficient way to improve local medical capabilities during disasters; however, problems and risks that warrant reflection and improvement also existed.

This caused further spread of the pandemic and resulted in a high mortality rate of about $4.9 \%{ }^{1}$ Before the current pandemic, Wuhan had already taken preparatory measures for disaster prevention and mitigation, such as building a disaster preparedness centre and setting up storage rooms for essential materials in the community. ${ }^{2}$ However, the role of the traditional approach in preparing for natural disasters was very limited during this pandemic and is thus facing an unprecedented challenge.

Since the COVID-19 outbreak, Wuhan has adopted three methods of admitting patients for treatment: designated hospitals, newly built temporary hospitals and Fangcang shelter hospitals. It has been proven that converting large-scale public venues such as stadiums and exhibition centres into 
Fangcang shelter hospitals, which serve as hospitals for isolation, treatment and disease monitoring of patients with mild symptoms, is the most effective way to control virus transmission and reduce mortality. ${ }^{3}{ }^{4}$ Converting large-scale public venues into Fangcang shelter hospitals is an important means to rapidly improve the function of the city's healthcare system during a pandemic. ${ }^{5}$ At present, the USA, the UK and some other countries have also been building similar Fangcang shelter hospitals. ${ }^{6}$ It is necessary to summarise the experience of Wuhan in building Fangcang shelter hospitals.

\section{SIGNIFICANCE OF AN EMERGENCY SHELTER DURING A DISASTER}

The construction of a shelter after a disaster is crucial to reducing the impact of disasters and protecting the lives of victims, as the shelter can provide essential living and medical conditions for them. There are many forms of shelter, including temporary structures made of plastic sheets, tents, prefabricated structures, existing large buildings and so on. ${ }^{7}$ The form selected depends on various factors, such as the type of disaster, climate, economics and estimated lifespan. For existing large buildings, Ansary et al suggested that schools, religious facilities and community centres could be used as shelters during disasters, and the vulnerability of these buildings should be evaluated in advance. In addition to providing an essential living environment and living conditions for the victims, the shelters can also be combined with a makeshift hospital to provide timely and effective medical care. Usually after natural disasters, plagues and wars, the limited medical resources in cities cannot meet the needs of a rapid surge of casualties over a short period of time. At such times, medical emergency measures are needed to quickly fill the gap in medical resources. ${ }^{9}$ For example, after the typhoid epidemic in Montreal, Canada in 1910, the local government converted the Northern Power Company's factory into an emergency medical site within 5 days to treat patients. During the Spanish influenza epidemic in 1918, 38\% of the hospital beds were placed in existing buildings, such as residences, hotels, factories and schools. ${ }^{10}$

During the COVID-19 pandemic, Wuhan converted large-scale public venues into Fangcang shelter hospitals, which provided essential living and medical conditions for isolated patients with mild symptoms as well as for suspected patients. Chen $e t a \hat{l}$ illustrated three key characteristics (rapid construction, massive scale and low cost) and five essential functions (isolation, triage, basic medical care, frequent monitoring and rapid referral, and essential living and social engagement) that set Fangcang shelter hospitals apart from other makeshift hospitals or emergency field hospitals. Using data from 21 January to 21 February 2020 published by the Chinese Health Commission, Yuwen found that the establishment of Fangcang shelter hospitals had significantly reduced patient mortality. ${ }^{11} \mathrm{Zhu}$ et a $a \tilde{l}$ stated that the rapid admission, low cost and the easing of public anxiety are the three advantages of building Fangcang shelter hospitals. Converting large-scale public venues into Fangcang shelter hospitals is an effective and efficient way to improve local medical capabilities during disasters; however, problems and risks that warrant reflection and improvement also existed.

\section{CHARACTERISTICS OF WUHAN FANGCANG SHELTER HOSPITALS}

After the high-level expert team of the National Health Commission had announced the human-to-human transmission of COVID-19 on 20 January, Wuhan successively set up designated hospitals, built new temporary hospitals, such as the Huoshenshan Hospital, and converted public venues into Fangcang shelter hospitals. A comparison of these three hospitals is shown in table 1.

The outcome of these three approaches indicates that Fangcang shelter hospitals were key to controlling the pandemic and reducing mortality in Wuhan. Fangcang shelter hospitals requisitioned existing large-scale public venues, ready for use after rapid renovation. These hospitals play an important role in four areas: (1) obviating within-household and community transmission, thus reducing the number of new infections and releasing pressure from designated and temporary hospitals; (2) expanding admission capacity to prevent the spread of the virus in the community; (3) patients in the hospital can get standard and effective treatment, reducing the proportion of patients with mild symptoms that progress into severe diseases; and (4) patients with severe diseases can be identified and transferred promptly, reducing the rate of mortality. ${ }^{412}$ Table 2 sets out the main characteristics of 16 Fangcang shelter hospitals in Wuhan.

Having examined the 16 Fangcang shelter hospitals in Wuhan, it can be concluded that the large-scale public venues expropriated during a pandemic have the following five key features:

\section{Located at the centre of an urban area, but away from susceptible areas}

Large-scale public venues often drive the economic development of urban areas and often located at the core of an urban spatial structure. If a pandemic affects a city dramatically, each venue in the centre of such an area can accommodate patients in this zone. This prevents the concentration of patients in a certain area which may result in cross-infection and increase the burden on medical resources and supplies. Meanwhile, the site should be away from high-density residential areas, schools and other densely populated areas in order to reduce the risk of virus transmission. In each district of Wuhan, one or two large-scale venues have been converted into Fangcang shelter hospitals. The deputy head of the district acts as the deputy director of the respective hospitals, and is responsible for managing and coordinating local medical supplies and other resources. 
Table 1 A comparison of designated hospitals, newly built temporary hospitals and Fangcang shelter hospitals

\begin{tabular}{|c|c|c|c|}
\hline Type of hospital & Designated hospitals & Newly built temporary hospitals & Fangcang shelter hospitals \\
\hline Approaches & $\begin{array}{l}\text { Designate several hospitals as } \\
\text { the designated hospitals to admit } \\
\text { patients. }\end{array}$ & $\begin{array}{l}\text { Build a temporary hospital that } \\
\text { meets the standards of respiratory } \\
\text { infectious disease hospitals to } \\
\text { admit patients. }\end{array}$ & $\begin{array}{l}\text { Requisition of public venues, such } \\
\text { as stadiums and civil buildings, to } \\
\text { convert into healthcare facilities to } \\
\text { admit patients. }\end{array}$ \\
\hline Date of opening & 22 January 2020 & 23 January 2020 & 5 February 2020 \\
\hline Capacity (beds) & 23532 & 2600 & 16000 \\
\hline Disadvantage & $\begin{array}{l}\text { Increase the risk of nosocomial } \\
\text { infection, and it is difficult to } \\
\text { provide different levels of care. }\end{array}$ & $\begin{array}{l}\text { Time-consuming and costly } \\
\text { construction, limited hospital beds. }\end{array}$ & $\begin{array}{l}\text { Public venues do not meet the } \\
\text { requirements of hospitals and } \\
\text { comfortable living conditions in } \\
\text { general. }\end{array}$ \\
\hline
\end{tabular}

The renovation of public venues in different areas can effectively relieve the urban emergency burden.

\section{Accessibility}

Large-scale public venues are often in the centre of a large metro area and are adjacent to multiple major arterial roads. Once these venues had been converted into Fangcang shelter hospitals as centres for receiving patients, supplies and staff support in that area, there was a high demand for convenient transportation. In addition, large-scale venues are often close to traditional hospitals, and patients whose symptoms deteriorate from mild to severe can be quickly transferred for further treatment. The Wuhan Living Room, for example, is located at the intersection of Wuhan's rapidly developing urban area, which is surrounded by trunk roads, subways and other transportation systems. It is a $15 \mathrm{~min}$ drive from the Tianhe Airport or Hankou Railway Station. This advantage, which is also an important factor in normal circumstances, made possible the construction of the largest Fangcang shelter hospital within 5 days. Moreover, the hospital is only $836 \mathrm{~m}$ away from the Jinyintan Hospital, which is one of the most important designated hospitals in Wuhan. It is not only convenient for patients with severe to critical COVID-19 to be transferred to the Jinyintan Hospital promptly, but it is also conveniently placed so the hospital can send experts to the site for guidance.

\section{Spacious outdoor area}

Large-scale public venues, where various large-scale competitive sports are often held, have ample outdoor space. The spacious field facilitates the entry and evacuation of numerous vehicles and people. ${ }^{13}$ As a shelter hospital, the spacious outdoor field enables the rapid arrival and evacuation of ambulances, the construction of temporary auxiliary tents, and the installation of medical facilities. For example, in the Wuhan Living Room exhibition complex, the National Emergency Medical Rescue Team and the China International Emergency Medical Team (Shanghai) set up 7 tents as passage for health workers and 13 tents as command centres and auxiliary rooms, which connected to the remote consultation centre and became the core of the Fangcang shelter hospital operation (figure 1).

\section{Spacious indoor space}

China's rapid economic development has stimulated the demand by urban residents for cultural and recreational activities. Many cities have spacious large-scale public venues. Most of these venues are long-span structures or frame structures with flat space and a stable indoor environment which can accommodate a substantial quantity of people and equipment. The large-scale stadium can be easily renovated and partitioned, and can provide essential living conditions for a surge of infected people during a pandemic. For example, the Wuhan International Expo Center, which was one of the first to be converted into a Fangcang shelter hospital in the first batch, has a total construction area of $127000 \mathrm{~m}^{2}$. After the renovation, it provided 1600 beds and treated 1848 cases before it was closed. ${ }^{14}$

\section{The power supply is reliable and easy to remodel}

Large public venues often hold a variety of big events, which require highly reliable power supply. The power supply system of such places is highly reliable and is easy to remodel to serve different needs. Medical instruments such as CT equipment in Fangcang shelter hospitals have higher requirements for power supply, and largescale venues can meet these requirements after minor 


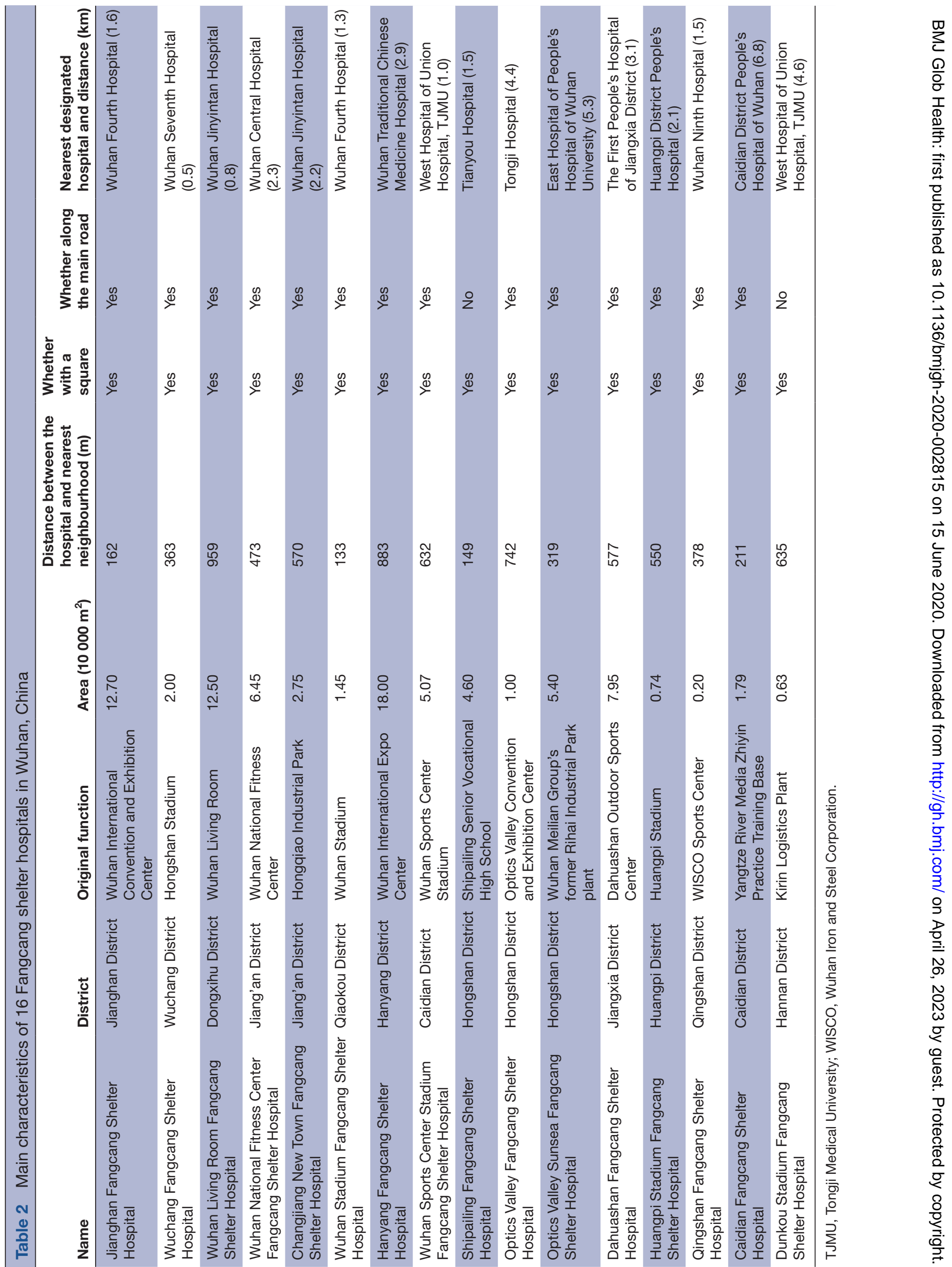




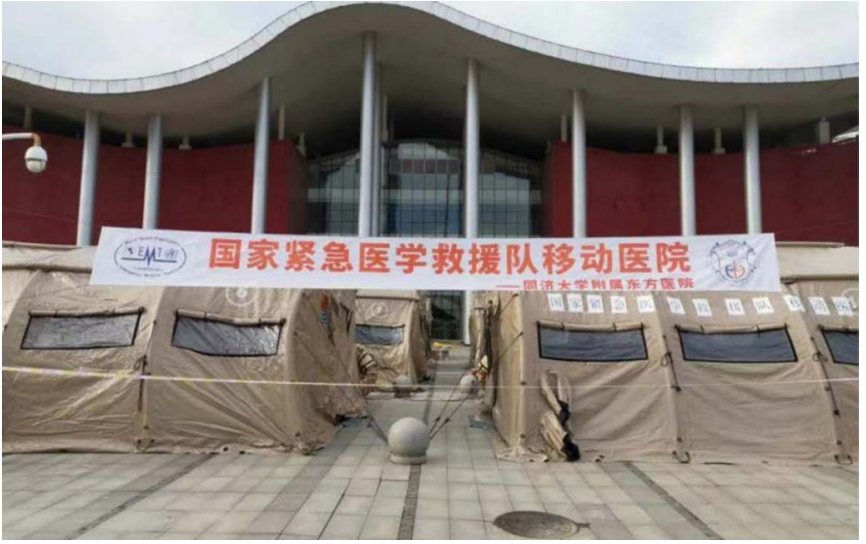

Figure 1 National Emergency Medical Rescue Team and China International Emergency Medical Team (Shanghai) at Wuhan Living Room (https://www.thepaper.cn/newsDetail_ forward_6733297)

remodelling. For example, in Wuhan Sports Center, the power distribution room uses dual power supply, and the two main power supplies both have a capacity of $3250 \mathrm{kVA}$, which has large-scale redundancy. The power supply system is equipped with a generator of $800 \mathrm{kVA}$ and an emergency power supply of $750 \mathrm{kVA}$. These effectively ensure that the demand for important loads is not disrupted. Moreover, the Wuhan Sports Center has had practical experience in power protection for the 7 th CISM Military World Games, and thus has a highly reliable power supply. ${ }^{15}$

In addition, these venues are required to meet the conditions for conversion into a shelter hospital, such as telecommunications, water supply and drainage, and fire safety facilities.

\section{KEY POINTS IN THE DESIGN OF FANGCANG SHELTER HOSPITALS}

During the design and renovation of Fangcang shelter hospitals, it was necessary not only to follow the standards of infectious disease hospitals, but to also take into consideration challenges, such as reconstructing the existing building with limited time and high-volume workload. Special attention should therefore be paid to the building layout, partition isolation, ventilation and sewage discharge.

\section{Architectural layout design and partition isolation}

The architectural layout of a hospital follows the "three zones and two passages' pattern, which includes a contaminated zone, a semiclean zone and a clean zone, passages for health workers, and passages for patients. A contaminated zone is the area where patients live and receive treatment, such as wards, treatment rooms, biohazard waste rooms, and patient admission and discharge registration rooms. The clean zone includes staff's dressing rooms, catering services, duty rooms and warehouses. Semiclean zones are areas between the clean and contaminated zones, such as medical staff offices, nurse stations and other areas that may be contaminated by patients.

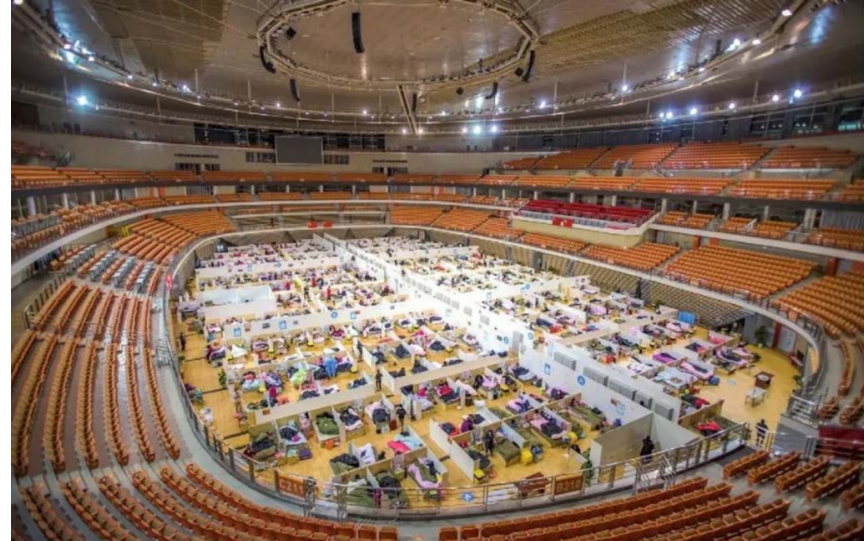

Figure 2 The layout of the Fangcang shelter hospital of Hongshan Stadium (http://www.xinhuanet.com/english/202003/03/c_138840039.htm)

The ward should be partitioned and meet evacuation standards. In each zone, there should be no more than 42 beds but at least two evacuation exits. The width of the evacuation exit should be no less than $1 \mathrm{~m}$ per 100 persons, and the distance between anywhere to the evacuation exit should not exceed $30 \mathrm{~m}$. The width of evacuation passages between the zones should not be less than $4 \mathrm{~m}$. The partition should be made of fire-resistant material, and the height should not be lower than $1.8 \mathrm{~m}$ (figure 2 ).

The architectural design should also include essential living facilities, such as toilets, barrier-free access and storage rooms. For example, for toilet facilities, foamblocked mobile toilets should be preferred, and medical staff's and patients' toilets should be separated. The men's toilet is configured according to one positon per 20 men and one postion per 10 women. The number can be adjusted according to the actual situation. Toilets should be built downwind, away from dining areas and water points.

\section{Ventilation}

The ventilation and air-conditioning systems of large public venues are mostly positive pressure systems and only a few are negative pressure systems. This does not meet medical requirements. The remodelling of the ventilation system should make the best use of the original systems, and change the air supply and exhaust strategies to form a pressure gradient between the clean zone, the semiclean zone and the contaminated zone.

Air purification and disinfection devices should be used for air-conditioning systems in a contaminated zone and a semiclean zone. If possible, the air-conditioning unit can be equipped with a clean air-conditioning system, and an ultraviolet disinfection lamp can be installed near the return air filter and the surface cooler. The exhaust air volume should be designed to be no less than $150 \mathrm{~m}^{3}$ / hour per person.

\section{Sewage}

The sewage from Fangcang shelter hospitals cannot be directly discharged. Temporary tanks for sewage 


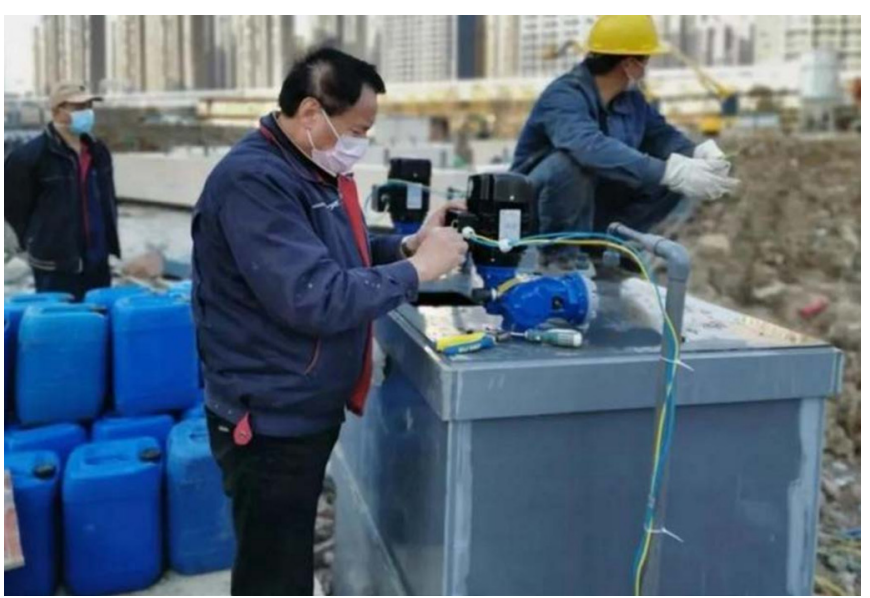

Figure 3 Renovation for sewage treatment at a Fangcang shelter Hospital (http://www.sasac.gov.cn/n2588025/ n2641611/n4518442/c13881088/content.html)

treatment should be set up. Chlorine and peroxyacetic acid can be applied to sterilise and disinfect the sewage. Using mobile hospital-specific plasma equipment for sewage treatment is also feasible. It is important to install an automatic monitoring system for water quality inspection at the treated sewage outlets to ensure that the discharged sewage meets the standards (figure 3).

\section{PROBLEMS IN THE CONSTRUCTION AND MANAGEMENT OF FANGCANG SHELTER HOSPITALS}

In the fight against the COVID-19 pandemic in Wuhan, the rational expropriation and conversion of large public venues into Fangcang shelter hospitals have played a vital role in the control of the epidemic. However, some problems emerged which warrant further reflection.

\section{Fangcang shelter hospitals were not included in the emergency action plan for epidemics}

In the early stage of the pandemic, Wuhan did not immediately implement measures to convert existing largescale public venues into Fangcang shelter hospitals. Instead, new temporary hospitals were built, such as the Huoshenshan Hospital and the Leishenshan Hospital, but their capability and capacity to admit, treat and quarantine patients were limited. In future urban planning and emergency action plans, large-scale public venues in cities should be prepared to be converted to medical emergency sites during disasters. The local emergency action plan should include details of the large public venues, together with the prerequisites and procedures for renovation.

\section{Large public venues are less prepared for conversion into emergency shelters}

The renovations can involve some complicated construction work, such as the remodelling of ventilation systems. Some Fangcang shelter hospitals were still undergoing construction of ventilation systems when they started to admit patients. In the future, medical emergency shelters should be included in the architectural design and construction plan of designated large-scale public venues. For example, the layout for a temporary hospital, including ward zones, treatment and work stations, should be planned in advance, and the installation interfaces of the ventilation system and sewage treatment system should be reserved, in order to manage air pressure gradient and prevent nosocomial infection in the future. During the initial design stage of large public venues, preparing for multiple disasters such as earthquakes, floods and fires should also be considered, and also provide interfaces for converting them into shelters during disasters. This can be summarised as the goal of 'One investment, Comprehensive disaster prevention'.

\section{Insufficient on-site management experience in Fangcang shelter hospitals}

During the early stage of operations of Fangcang shelter hospitals, some problems emerged which reflected insufficient on-site management experience, such as confusion with responsibilities and the high turnover of medical staff. The working team in Fangcang shelter hospitals was temporarily composed of local government and medical rescue teams from other provinces. Clarifying each person's responsibilities and ensuring the stability of the team are prerequisites to the effective operation of a shelter hospital. First, the government, community and medical rescue team should clarify their responsibilities. Government staff are responsible for hospital construction and deployment of resources. Community workers are responsible for maintaining the order of patients in the hospital, and medical staff are responsible for medical assistance. Second, the main function of Fangcang shelter hospitals is the admission and isolation of patients with mild symptoms, and thus require fewer medical staff. The medical manpower can be reasonably allocated to avoid waste of medical resources. Finally, medical rescue teams from other provinces should be planned and assigned holistically. Transferring medical staff back and forth between different Fangcang shelter hospitals should be avoided in order to reduce the risk that comes with medical staff not being familiar with the new hospital and the patients.

\section{CONCLUSION}

During the COVID-19 pandemic, traditional approaches to disaster preparedness have demonstrated intrinsic problems, such as poor economic performance, inefficiency and lack of flexibility. The conversion of largescale public venues into medical emergency sites in order to increase the medical capacity of an urban area is one of the most important aspects of disaster preparedness. This valuable experience in Wuhan will help other countries in their battle against the current COVID-19 pandemic and will also contribute to disaster preparedness and mitigation in the future. 


\section{Author affiliations}

'Department of Construction Management, School of Civil Engineering, Tsinghua University, Beijing, China

${ }^{2}$ Department of Orthopedic Surgery, Shanghai Jiao Tong University Affiliated Sixth People's Hospital, Shanghai, China

${ }^{3}$ Specialty \& Inpatient Center, ParkwayHealth Shanghai, Shanghai, China ${ }^{4}$ Department of Emergency, Shanghai East Hospital, Tongji University School of Medicine / National Emergency Medical Team (Shanghai), Shanghai, China ${ }^{5}$ School of Arts and Media, Tongji University, Shanghai, China

${ }^{6}$ Emergency Management Office, Shanghai East Hospital, Tongji University School of Medicine, Shanghai, China

Contributors DF, SP and ZL wrote the manuscript, TY, BJ and DG analysed the data. BS, JH, TW and ZL checked and guided this work.

Funding The authors have not declared a specific grant for this research from any funding agency in the public, commercial or not-for-profit sectors.

Competing interests None declared.

Patient and public involvement Patients and/or the public were not involved in the design, or conduct, or reporting, or dissemination plans of this research.

Patient consent for publication Not required.

Provenance and peer review Not commissioned; externally peer reviewed.

Data availability statement Data are available in a public, open access repository.

Open access This is an open access article distributed in accordance with the Creative Commons Attribution Non Commercial (CC BY-NC 4.0) license, which permits others to distribute, remix, adapt, build upon this work non-commercially, and license their derivative works on different terms, provided the original work is properly cited, appropriate credit is given, any changes made indicated, and the use is non-commercial. See: http://creativecommons.org/licenses/by-nc/4.0/.

ORCID iD

Tao Wang http://orcid.org/0000-0002-5138-7116

\section{REFERENCES}

1 Coronavirus (COVID-19) mortality rate. Available: https://www. worldometers.info/coronavirus/coronavirus-death-rate/\#nhc [Accessed 17 May 2020].

2 Jianguo $\mathrm{G}$. The role of reserve storehouse set up by central government in earthquake emergency rescue. Recent Developments in World Seismology 2004;8:22-8.

3 Chen S, Zhang Z, Yang J, et al. Fangcang shelter hospitals: a novel concept for responding to public health emergencies. Lancet 2020;395:1305-14

4 Pan A, Liu L, Wang C, et al. Association of public health interventions with the epidemiology of the COVID-19 outbreak in Wuhan, China. JAMA 2020;323:1915-23.

5 Zhu W, Wang Y, Xiao K, et al. Establishing and managing a temporary coronavirus disease 2019 specialty hospital in Wuhan, China. Anesthesiology 2020;132:1339-45.

6 "Square Cabin" Hospital in New York, USA. Available: https://news. ifeng.com/c/7vEIDpRqoLo\#p=1 [Accessed 31 Mar 2020].

7 Abdulrahman B, Garritya S, Moodleya K. An overview of the design of disaster relief shelters. Procedia Economics and Finance, 2014:18-31.

8 Ansary MA, Reya MY, Jahan I. Rethinking the public building as post-disaster shelters in the context of old Dhaka. Proceedings of the 9th US National and 10th Canadian Conference on Earthquake Engineering, 2010.

9 Hirayama K, Hirota N. Mobile hospital system. U.S. patent No. 6,179,358, 2001: 358 .

10 Adams A. Borrowed buildings: Canada's temporary hospitals during World War I. Can Bull Med Hist 1999;16:25-48.

11 Yuwen C, Liu X, Xu G, et al. The Effects of "Fangcang, Huoshenshan, and Leishenshan" Makeshift Hospitals and Temperature on the Mortality of COVID-19. medRxiv.

12 Dickens BL, Koo JR, Wilder-Smith A, et al. Institutional, not homebased, isolation could contain the COVID-19 outbreak. The Lancet 2020;395:1541-2.

13 Zhe K, Ruipu S, Xiaopeng B. The converting mode of large-space public construction function against disasters. International disaster and risk Conference, IDRC DAVOS, 2010.

14 Holding up the hope of life-Wuhan Fangcai Hospital successfully completed its mission. Available: http://cpc.people.com.cn/n1/2020/ 0311/c431601-31627235.html [Accessed 31 Mar 2020].

15 Development Zone Power Supply Company escorts the construction of "Square Cabin Hospital" of Wuhan Sports Center. Available: http://hb.ifeng.com/a/20200206/8176351 0.shtml [Accessed 31 Mar 2020]. 